\title{
Disruptive innovation and EU health policy
}

\author{
Bengt Jönsson ${ }^{1}$
}

Published online: 26 October 2016

(C) Springer-Verlag Berlin Heidelberg 2016

\section{Another idea whose time has come?}

The USA may not have the best health care system in the world. But as a source for innovations in health policy they are sure number one. Diagnosis related groupings (DRG), health technology assessment (HTA), and value-based health care are just some examples of ideas that have originated from the US and got widespread attention over the world. These ideas have been developed as a response to specific problems and issues in the US health care system. There is thus a need to carefully reflect on how they can be put to best use in a European context.

Disruptive innovation is another example of a concept developed in the US by professor Clayton M. Christensen at Harvard Business School in 1997 [1]. The term is used to define innovations that "enable a larger population of lessskilled, less-wealthy people to do things in a more convenient, lower-cost setting, which historically could only be done be specialist in less convenient settings". Applied to health care this should be innovation that moved technology from hospitals and specialist, and empowered the patient to be in greater control and at the same time reduced costs $[2,3]$. With the usual delay of about 20 years for important new ideas to mature and come into action, it is now time for us to examine how this can be used for development of health policy in Europe.

The Expert Panel on effective ways of investing in health $(\mathrm{EXPH})$ was given the mandate from the EC to give an opinion on the potential role of "disruptive innovation"

Bengt Jönsson

Bengt.Jonsson@hhs.se

1 Department of Economics, Stockholm School of Economics, Stockholm, Sweden as a tool in European health policy. Specifically the tasks were to build a simple taxonomy of disruptive innovation, and to assess drivers and barriers for development and successful implementation of disruptive innovation. The opinion reflects the different perspectives of the members of the panel in terms of the countries and disciplines they represents [4]. This note was prepared during the work with the proposal as one panel member, and reflects a personal and health economics perspective on the issues.

\section{Technology and innovation}

The remit for the EXPH opinion on "Disruptive innovation" states that technology is the major driver of increasing costs of health care. This may be debated, since innovations can be cost saving as well, but let us leave that debate for the moment. The other side of that statement is that changes in technology, inside and outside the health care, are responsible for the major improvements in health.

Technology is in its most general way defined as the use of knowledge for defined purposes. Innovation for improved health can thus be described, as changes in our knowledge how we can achieve desired health goals to a greater extent and/or with reduced input of resources.

The key aspect of innovation is thus improvement in knowledge or information. An important distinction is between embodied and disembodied technological progress/innovation. When the information partly is built into a device or a drug it is called embodied. Embodiment facilitates patent and marketing and about $20 \%$ of health care expenditures are for drugs and devices in the EU. Technologies can also be embodied in persons that develop specific skills, for example surgical procedures. 
Changes in knowledge how to improve organisation and management of health care systems can also be classified as innovations. One example may be the introduction of the DRG classification system for hospital activities in the 1970s, and recently the development of systems for integrated health care in the US. In Sweden, the development of principles and practices for commissioning of care from private providers can also be described as an (disruptive?) innovation [5].

Innovation can also be improved information about risk factors for health. For example, the studies leading to the establishment of the link between smoking and lung cancer provided an innovation that could be used be the general public to improve health. This innovation also leads to the development of embodied technologies, for drugs and devices aimed at helping individuals to quit smoking.

It is interesting to note that Christensen suggest "embodiedness" as a solution to the problem for disruptive innovation to be adapted and diffused.

\section{Disruptive innovation}

Innovation can be classified in many different ways and none is right or wrong, but some may be more useful than other. The selection of a specific category of innovations as "disruptive" can be useful if there are specific policy issues related to either the incentives for development of this type of innovation or if there are specific issues related to its application.

While economists since long had been occupied with classification of innovations as productivity increasing and capital or labour saving, Schumpeter in 1942 invented "creative destruction" as a concept for analysis and policy [6]. The concept was introduced first within an analysis of the long-term survival of capitalism, where it was used to denote an endogenous replacement of old ways of doing things with new ways, that will destroy the capitalist structure by its successes. In opposition to Karl Marx, who believed that capitalism would be destroyed by its enemies. It was later linked to his writings on the role of the entrepreneur and large companies, respectively in the process of innovation. His observation was that the most important innovations could not be described by conventional theory, and he put forward the entrepreneur as an important factor of production for what could be called "disruptive innovation". This was in his view innovations that totally transformed the way an industry or market was organized and worked. IKEA and Ingvar Kamprad could be an example of this combination of an innovation and an entrepreneur, including both a new product (the "flat package" for transport of furniture) and a new distribution system, where the customer has an important role to keep costs low. It is also an innovation that was met with strong opposition from other firms in the market that were challenged by the new approach to selling furniture. In later writings Schumpeter discussed the role of large companies, with resources for research and development, in the innovation process.

While disruptive innovation can be an important concept for policy analysis, this does not mean that other types of innovation are less desirable (example the Hawthorne effect; even without any changes in the production technology or the organisation of production, you may observe continuous improvements in productivity). Incremental innovation can be very important, as well as more radical innovation that may not be classified as disruptive.

\section{Adaption and diffusion of innovation}

There is a large body of literature around diffusion of innovation. While there are some general observations, for example the $\mathrm{S}$-shaped diffusion curve with early and late adopters, there are important differences between how different technologies are adopted. One concept used to describe technologies that are quickly adopted is that they are compatible with existing practices. A special interest for disruptive innovation could be to look to what extent the innovation is compatible with existing "value system" or "power structures". It is not uncommon that special rules, regulations or payments are needed to get acceptance for the new technology. For example, when cars were allowed into the Engadine valley in eastern Switzerland, it was on the condition that a horse should pull them, once they got over the Julier pass.

\section{Disruptive innovation in health care}

Christensen's definition of disruptive technology focuses on ease of use, and potential cost reductions. The example of drug eluting stents as a disruptive technology seems questionable. While PCI may be considered a disruptive technology, since it at least partly replace $\mathrm{CABG}$, facilitate acute treatment, is less traumatic for the patient, and transfer power from surgeons to cardiologists and radiologists. But it can hardly be described as "ease of use". Evaluations also indicate that over the long term, costs and outcome for many patients are the same for PCI and CABG. The development from bare metal to drug eluting stents seems to me to be an incremental innovation, where the potentially better outcomes will come at a price that may be cost-effective, but not cost saving.

Lewis Thomas made half a century ago the observation that the health care system did not take any great interest in 
technology and innovation [7]. "It seems taken for granted that the technology of medicine simply exists, take it or leave it, and the only major technologic problem which policy-makers are interested in is how to deliver today's kind of health care, with equity, to all the people ". In this beautifully written paper, he offers an alternative definition of disruptive technology in health care. He makes a distinction between non-technology, halfway technologies and high technology. Non-technology represents a situation where there is not very much that can be done to change the course of the disease. However, I lot can be done to help the patients through the episode of illness, and this is a technology that is both commonly used and highly appreciated. Halfway technology may be described as a radical innovation, where it becomes possible to influence the course of the disease and improve outcome. The technology is often performed in hospitals and expensive. It could be exemplified with radiotherapy and surgery for some cancers, or treatment of polio victims in the iron lung. Dialysis and transplantation for chronic renal failure could also be seen as half way technologies. Examples could also be found in biological pharmaceuticals for MS and RA introduced in the 1990s.

The third stage of technology in Thomas classification is "high technology", which is based on a true understanding of the disease. The technology could offer prevention and cure at a low cost. An example could be polio vaccination that eliminates the need for resources for acute care and rehabilitation. Another example could be drugs for reduction of acid secretion, $\mathrm{H} 2$ receptor antagonists and proton pump inhibitors that eliminated the need for surgery for ulcer disease, and after some time was available without prescription to be used as self-medication.

One option could be to classify disruptive innovation as the move from halfway to high technology. The specific criteria need to be worked out, but true understanding of the disease, opportunities to make it available to all at a low cost, and significant improvement in outcome could be the major candidates.

This definition may be less useful when applied to innovations in organizational and management of health care. Such innovations may be difficult to relate directly to specific diseases and interventions. However, the objectives of making health care more accessible, convenient and more cost-effective would be the same.

Developments in information and communication technologies, including e-health and $\mathrm{m}$-health, would be of particular interest as examples of innovations outside health care, with strong implications both for organisation and management of health care, and for patient involvement in and influence over the treatment processes. However, not all communication and information technologies in health care are disruptive. The substitution of paper records with electronic records may reduce costs and improve outcomes without necessary creating new business models and value networks.

\section{Policy relevant definitions and analyses}

The two main policy issues are incentives for disruptive innovation and adoption and diffusion of such innovations. The first policy issue involve what economists call incentives for dynamic efficiency. How do we create incentives for development of valuable new technologies? Are the current incentives in favour of incremental or radical innovation (halfway technology) rather than disruptive innovation? Should more research be put into basic understanding of the disease, rather than the development of expensive hafway technologies? What is the role of health policy for the direction of innovation? Do reimbursement systems favour half way technologies? What about other health policies?

Similar policy questions could be asked about adaptation and diffusion of technologies. One example is issues related to personalized medicine; do we need large scale public investment in testing, or should this be left to the market for individual decisions. The literature on diffusion of medical technologies offers a theoretical framework for further discussions. The classic reference is Rogers and many studies have been published using his model, and it may be a start to understand the specific issues related to diffusion of disruptive innovation [8]. Don Berwick is usually an interesting observer of the medical market place, and his review from 2003 may provide further insight [9].

Christensen notes how "strong institutional forces fight simpler alternatives to expensive care, because those alternatives threatens their livelihood." He claims that this (monopolistic?) behaviour is not in the interest of the industry, and advocate opening up the market to competition. However, it is not obvious how competition should be introduced to support development of health care systems towards the dual goals of efficiency, both static and dynamic, and equity in health and health care delivery [10].

Christensen singles out four specific solutions to the present crises for the US health care system; (1) createand then embrace-a system where the physicians skill level is matched to the level of the medical problem, (2) invest less money in high-end complex technologies, and more in technologies that simplify complex problems, (3) create new organizations to do the disrupting and (4) overcome the inertia of regulation.

All four types of solutions may be relevant from a European perspective as well. Even if many European countries have developed further than the US on point one, support of self care and primary care and substitution of 
tasks between doctors and nurses, there are a number of issues related to innovation for the optimal use and training of health care professionals, not only physicians. The second point does not specify who is investing the money, but also in Europe it is mainly the private sector that invests in development of new technologies, and the public sector supports basic research. Private-public initiatives like IMI are under way, but creating the right incentives for investments in the desired type of technologies is a complicated process, where countries and firms collaborate and compete at the same time. It is well known that it is difficult to do new things in old institutions. But creating new institutions, and dismantling old institutions, is a tedious process and not accomplished over night. It is noticeable that the purchaser-provider split instituted in many health care systems, has taken decades of learning by doing (also mistakes) to create and develop. Changing regulation seems the easiest, but the legislative process needed to change regulations takes time, and can easily be delayed by interest opposed to the changes.

\section{Conclusion}

Disruptive innovation is a new concept, but the issues involved has been observed, studied and reacted on for a long time. With the growing importance of innovation for health policy in European health care systems that face strong restrictions on cost, looking from a new perspective may help to more clearly see the issues, and what can and should be done about them.

\section{References}

1. Christensen, C.M.: The Innovator's Dilemma: When New Technologies Cause Great Firms to Fail. Harvard Business Press, Boston, Massachusetts, USA (1997)

2. Christensen, C.M., Bohmer, R., Kenagy, J.: Will disruptive innovations cure health care? Harv. Bus. Rev., Sept-Oct (2000)

3. Christensen, C.M., Grossman, J.H., Hwang, J.: The Innovator's Prescription: A Disruptive Solution for Health Care. McGrawHill, New York, USA (2008)

4. EXPH. Disruptive innovation. Considerations for health and health care in Europe. Expert Panel on effective ways of investing in health. Report. http://www.ec.europa.eu/health/expert_panel/ opinions/docs/ (2015). Accessed 1 Oct 2016

5. EXPH. Best practices and potential pitfalls in public health sector commissioning from private providers. Expert Panel on effective ways of investing in health. Report. http://www.ec.europa.eu/ health/expert_panel/opinions/docs/ (2016). Accessed 1 Oct 2016

6. Schumpeter, Joseph A.: Capitalism, Socialism and Democracy, In: Impact Books, 1st edn. Harper and Brothers, United States (1942)

7. Thomas, Lewis: The technology of medicine. N. Engl. J. Med. 285, 1366-1368 (1971)

8. Rogers, E.: Diffusion of Innovations, 5th edn. Simon and Schuster, New York. ISBN 978-0-7432-5823-4 (2003)

9. Berwick, D.M.: Disseminating innovations in health care. J. Am. Med. Assoc. 289(15), 1969-1975 (2003)

10. EXPH Competition among health care providers. Investigating policy options in the European Union. Expert Panel on effective ways of investing in health. Report. http://www.ec.europa.eu/ health/expert_panel/opinions/docs/008_competition_healthcare_ providers_en.pdf (2016). Accessed 1 Oct 2016 